\title{
Научная статья
}

УДК 81'27:811

DOI: 10.17748/2686-9969-2020-3-4-71-83

\section{Ольга Леонидовна Бессонова}

ГОУ ВПО «Донецкий национальный университет»

$$
\text { г. Донецк, Украина }
$$

Университет Св. Кирилла и Мефодия в Трнаве

г. Трнава, Словакия

ORCID iD: http://orcid.org/0000-0002-5171-9790

e-mail: o.bessonova@donnu.ru,

\section{ОТРАЖЕНИЕ ПРЕДСТАВЛЕНИЙ О СОЦИАЛЬНЫХ РОЛЯХ В КАРТИНЕ МИРА НОСИТЕЛЕЙ НЕБЛИЗКОРОДСТВЕННЫХ ЯЗЫКОВ}

Bведение. Статья посвящена анализу отражения представлений о гендерных социальных ролях в концептуальной и языковой картине мужчин и женщин.

материалы и методы. Анализ базируется на материале лингвистического эксперимента, проведенного с носителями английского и украинского языков.

Результаты исследования. Результаты эксперимента свидетельствуют об отличиях в представлениях носителей английского и украинского языков о социальных ролях. Как показывает анализ материала, в украинском социуме общественная сфера ассоциируется в большей степени с профессиональной деятельностью мужчин и женщин, причем отмечается высокая степень ориентации женщин на материнство. В английском языке за пределами семьи определяются в основном мужские роли, а роли женщин являются в основном семейными и находятся в сфере личных, эмоциональных связей.

Обсуждение и заключения. Анализ социальных ролей показывает, что для украинского языкового сообщества в большей степени, чем для англоязычного, характерна установка на традиционную патриархальную семью, в которой женщина является хранительницей очага, организатором мужского потребления, а мужчина - хозяином и главой семьи. Полученные результаты позволяют установить системную корреляцию языковой структуры и структуры социальной, установить корреляции между лингвистическими явлениями и полом коммуникантов.

Ключевые слова: социальная роль, гендер, концептуальная картина мира, языковая картина мира, эксперимент, неблизкородственные языки

Цитирование: Бессонова О.Л. Отражение представлений о социальных ролях в картине мира носителей неблизкородственных языков. Педагогика: история, перспективы. 2020. Том. 3. № 4. с. 71-83.

DOI: $10.17748 / 2686-9969-2020-3-4-71-83$ 


\title{
Original article
}

\author{
Olga Leonidovna Byessonova \\ Donetsk National University, Donetsk, \\ University of Ss. Cyril and Methodius in Trnava \\ Trnava, Slovakia \\ ORCID iD: http://orcid.org/0000-0002-5171-9790 \\ e-mail: o.bessonova@donnu.ru,
}

\section{SOCIAL ROLES AS VIEWED BY SPEAKERS OF NON-COGNATE LANGUAGES}

Introduction. The article addresses the reflection of ideas about gender social roles in the conceptual and linguistic worldview of men and women.

Materials and methods. The analysis is based on the material of the linguistic experiment conducted with native speakers of such English and Ukrainian.

Results. The results of the experiment reveal the differences in the perception by the native speakers of English and Ukrainian of gender social roles. As the analysis of the material shows, in the Ukrainian society, the public sphere is associated to a greater degree with the professional activities of men and women, and there is a high degree of orientation of women towards motherhood. In English, outside the family, mainly male roles are defined, and the roles of women are mainly family and are in the sphere of personal, emotional ties.

Discussion and Conclusions. The analysis of social roles shows that the Ukrainian linguistic community, to a greater extent than the English-speaking, is characterized by an orientation towards the traditional patriarchal family, in which a woman is the keeper of the hearth, the organizer of male consumption, and the man is the owner and head of the family.

The results obtained in the course of the experiment enable to establish a systemic correlation between the language structure and the social structure, to establish correlations between the language phenomena and the gender of the communicants.

Keywords: social role, gender, conceptual worldview, linguistic worldview, experiment, non-cognate languages

For citation: Byessonova O.L. Social Roles as Viewed by Speakers of Non-Cognate Languages. Pedagogy: history, perspectives. 2020. Vol. 3. No.4. PP. 71-83

DOI: 10.17748/2686-9969-2020-3-4-71-83 (In Russ., abstract in Eng.).

\section{Вводные замечания}

Данная статья посвящена описанию специфики отражения представлений о социальных ролях в концептуальной и языковой картине мужчин и женщин в неблизкородственных языках. Гендер рассматривается как один из параметров человеческой личности, включающий в себя не только пол как биологическую субстанцию, но и как культурно обусловленный мыслительный конструкт. Таким образом, гендер входит в число когнитивных ресурсов как отдельной личности, так и общества. Следовательно, гендер является параметром исследования личности с точки зрения ее реализации в процессе коммуникации. Гендер обладает внелингвистическим статусом и является когнитивным феноменом (как часть индивидуального сознания и коллективного сознания). Он проявляется в стерео- 
типах и в речевом поведении людей. Изучение роли полов в развитии культуры, их символического и знакового выражения в философии, истории, психологии, языке, литературе и искусстве позволяет исследовать новые аспекты развития общества, глубже проникнуть в суть происходящих процессов (см., например, работы $[12 ; 14 ; 17 ; 25 ; 27 ; 28 ; 29])$. Гендерный анализ позволяет отойти от традиционных трактовок тех или иных явлений, дает возможность описать языковой материал с точки зрения представлений о понятиях “мужественное” и “женственное”, которые являются компонентами культуры общества и подвергаются непрерывным изменениям в ходе исторического развития. Проявление маскулинности и фемининности можно наблюдать в самых разных сферах, в частности в типах поведения, в различных видах социальной активности, а также в языке, описывающем эти феномены.

Роль и функционирование гендерного фактора в разных языках не совпадают. Возможны также расхождения в структуре ценностной иерархии, базовых оценочных концептов, на которые оказывает самое непосредственное влияние гендерный фактор.

Гендер является понятием, с которым связаны и многие различия, касающиеся представлений о гендерных ролях, то есть «общезначимых представлений о функциях мужчин и женщин в обществе и отношениях, которые складываются в ходе этой деятельности» [1]. Гендерный подход в целом предполагает, что различия в поведении и восприятии мужчин и женщин определяются не столько их физиологическими особенностями, сколько такими социальными факторами, как воспитание и распространенными в каждой культуре представлениями о сущности мужского и женского.

\section{Определение ключевых понятий исследования}

Данное исследование опирается на тезис о том, что каждое языковое сообщество имеет свою коммуникативную структуру, основывающуюся на системе социальных ролей, норм и ценностей, которая репрезентируется в речевом поведении коммуникантов - носителей языка. Система социальных ролей отражает структуру общества и является детерминирующим гендер фактором. Индивиды, определенные референционно, совпадают чаще всего с понятием роли, которая является частью организации ментального пространства в качестве особой сущности с соответствующим значением [2]. Человек включается в большое число социальных систем разного уровня, которые определяют его мышление, оказывают на него внутреннее воздействие. Социальной системой может быть семья, круг друзей, коллектив, общественные организации, рабочие группы, национальные общности и т.д. Становясь частью структуры какой-либо системы, ее элементом, человек исполняет различные социальные роли, включаясь, таким образом, в жизнь общества, принимая или отвергая распространенные в обществе нормы и ценности.

Существуют различные определения ключевого понятия нашего исследования. Как отмечает А.Д. Петренко, в социологии получило распространение понятие “социальной роли”, под которой понимаются различные формы общественного поведения человека [7]. По мнению Я. Щепанского, «роль - это относительно постоянная и внутренне связанная система поступков (действий), являющихся реакциями на поведение других лиц, протекающими в соответствии с более или менее четко установленным образцом, поступков, которых группа ожида- 
ет от своих членов» [10, с. 71]. И.С. Кон понимает под ролью функцию, «нормативно одобренный обществом образ поведения, ожидаемый от каждого, занимающего данную социальную позицию... То, насколько поведение лица соответствует общественным или групповым ожиданиям, служит критерием оценки выполнения им данной социальной роли» [3, с. 23].

Лингвистический аспект изучения социальных ролей, связанный с гендерной принадлежностью человека, является одним из ключевых аспектов исследуемой проблемы. В своей монографии “Социофонетическая вариативность современного немецкого языка в Германии" А.Д. Петренко представляет подробный обзор работ, посвященных соотношению особенностей ролевого поведения человека со структурными и стилистическими свойствами его речи $[4 ; 5 ; 8 ; 9 ; 13 ; 15$; 18; 21 и др. ]. Большинство лингвистов сходятся во мнении о том, что интерпретация речевого поведения не может обойтись без учета и анализа тех ролей, которые играет человек в каждом акте коммуникации. Рассматривая теорию речевого поведения в контексте популярной в социологии “ролевой теории", А.Д. Петренко отмечает, что категория социальной роли характеризуется взаимодействием следующих признаков:

- социальная роль представляет собой объективный поведенческий комплекс, принципиально независимый от произвола отдельного индивидуума;

- содержание социальной роли определяется и изменяется общественными отношениями, а не отдельными индивидуумами;

- важным компонентом социальной роли является ожидание окружающих чего-то от поведения индивида в конкретной социальной ситуации общения; отклонения от правил, предписываемых данной ролью, являются нарушениями норм социального поведения [7]. Данные признаки составляют в совокупности концепцию социальной роли, при которой общественные отношения рассматриваются в качестве относительно закрытой системы социальных норм. Действие этих норм независимо от конкретного индивидуума, а их проявление заключается в различных ролевых ожиданиях в процессе общения со стороны окружающих. При этом конкретная систуация общения выполняет особенную функцию, поскольку роль представляет собой совокупность действий и способов поведения, ожидаемых в конкретной ситуации друг от друга коммуникативными партнерами. Она основывается на социальном положении (позиции, статусе) индивидуума и связанной с ним функции лица в конкретной ситуации общения. Каждому индивидууму свойственно исполнение большого числа ролей в обществе, связанных, например, с его семейными или профессиональными обязанностями.

Ролевая теория родилась в русле социальной психологии и социологии, тем не менее она пересекается со многими лингвистическими проблемами. Так, в частности, она используется при анализе речевого поведения в конкретных коммуникативных ситуациях [16, с. 49], когда происходит осуществление вербальных планов и намерений говорящих. Словесные репертуары коммуникантов, т.е. активно реализуемый словарь и синтаксис, также рассматривают как реализацию ролевых репертуаров [24]. По мнению Е.Ф. Тарасова, «через понятие роли может быть описано членство личности в различного рода группах. Группа является субъектом ролевых экспектаций, они контролирует степень соответствия ролевой деятельности технологическим и этическим правилам, сформулированным этой группой» [9, с. 89-90]. 


\section{Лингвистический эксперимента как метод исследования представлений о социальных ролях носителей неблизкородственных языков}

В рамках исследования в 2002 году был проведен лингвистический эксперимент, в котором приняли участие 250 мужчин и женщин - носителей английского и украинского языков. Участникам эксперимента была предложена анкета, содержащая вопросы, относящиеся к опыту респондентов и охватывающие следующие области: демографическая информация (возраст, пол, образование, семейное положение, род занятий); мнение о социальных ролях, присущих мужчинам и женщинам; представление о ценностях, важных для женщин и мужчин, мнение об их положении в иерарархической системе ценностей; мнение о системе гендерных стереотипов; отношение к понятиям “женское / женственное”, “мужское / мужественное" и их репрезентация в языковой картине мира, представленная в шкалированном виде; мнение о существовании языковой дискриминации женщин, отношение к этому явлению, осведомленность о способах преодоления этого явления; отношение к “мужскому” и “женскому” стилям в языке, представления об особенностях этих стилей; примеры типичных "мужских" и “женских" оценочных предложений из личного опыта информантов. Результаты опроса легли в основу описания базовых гендерных концептов английского и украинского языков, особенностей языка женщин и мужчин в исследуемых языках. Полученные данные описаны исходя из гендерного принципа, т.е. языковой материал представлен с точки зрения представителей обоих полов. Сопоставительное описание этих основополагающих культурных концептов позволяет пролить свет на универсальные характеристики, которые являются общечеловеческими, а также выявить отличия, обусловленные спецификой структуры исследуемого языка, а также менталитетом языкового сообщества. Фрагмент эксперимента, связанный со спецификой отражения социальных ролей в концептуальной и языковой картинах мира мужчин и женщин, позволяет вскрыть системную корреляцию языковой структуры и структуры социальной и обнаружить каузальные связи в том или ином направлении, установить корреляции между лингвистическими явлениями и фактами общественной жизни, а именно полом коммуникантов.

\section{Результаты исследования}

\section{1. Социальные роли мужчин и женщин в английском языке}

В проводимом лингвистическом эксперименте в центре внимания были социальные роли, обусловленные постоянными социальными характеристиками человека: его социальным положением и профессией, возрастом, полом, положением в семье, поскольку именно роли, связанные с постоянными характеристиками, оказывают непосредственное влияние на поведение и образ жизни человека, формируют его личностные качества.

Результаты эксперимента показывают, что языковое сообщество делится на две части: домашний мир женщин и общественный мир мужчин с соответствующими полам социальными ролями. Ученые считают, что дети обоего пола всегда осуществляют первую идентификацию со своей матерью и, оставаясь возле женщины, усваивают более понятные семейные роли женщины и состояние женственности, а не мужские роли и мужественность [22]. Следовательно, становление мужчины проходит сложнее, чем женщины, из-за тех сдвигов в идентификации, которые должен пройти мальчик для достижения ожидаемой половой 
идентификации и осуществления соответствующей полу роли. Таким образом, мужчины чаще всего отождествляют себя с определенным культурно обусловленным стереотипом мужской роли, тогда как женщины имеют склонность к специфической идентификации с определенными аспектами роли своей собственной матери. Женские роли являются в основном семейными (англ. home-maker 'хозяйка дома, мать семейства, жена, создающая уют', domestic affairs 'домашние дела', family 'семья', childcare 'забота о детях', cooking 'приготовление пищи', sewing 'рукоделие', cleaning 'уборка') и находятся в сфере личных, эмоциональных связей. Вероятно, что такое исключительное и первостепенное значение семьи для женщин исходит из их биологических и половых отличий от мужчин. В противоположность этому мужские роли определяются в основном за пределами семьи (англ. work, career 'работа, карьера', authority figures 'представители власти', protectors 'защитники', leaders 'лидеры', managers 'менеджеры', decision-makers 'принимают решения', engaged in politics 'заняты политикой', sciences 'занимаются точными науками'). Хотя оба пола являются частями как семьи, так и внесемейного мира, разделение труда токово, что женщина занята в первую очередь в семье, институте отношений, мужчина - нет. Т. Парсонс и другие теоретики-феминисты [26] указывают, что именно профессиональная роль мужа, отца является главным определяющим фактором классового статуса. Хотя семьи все больше и больше зависят от дохода обоих супругов, социальное положение идеологически является следствием того, чем занимается мужчина. Соответственно, на жену смотрят, как на получающую свой статус и социальное положение от него, даже если она вносит свой вклад в поддержание стиля и уровня жизни семьи. Таким образом, женщина воспринимается как представительница семьи, а мужчина как независимая личность, которую считают главой семьи и добытчиком.

В целом и мужчины, и женщины сходятся во мнении относительно социальных ролей своего и противоположного пола. Однако женщины-респондентки предложили более объемный в количественном отношении набор социальных ролей для обоих полов. Женская оценка ролей собственного пола более позитивна, чем оценка противоположного пола (англ. caretaker 'человек, заботящийся о семье', interested in the arts 'интересуются искусством', giving peace and tranquility 'несут мир и спокойствие'). Эффект негативной оценки мужчин усиливается с помощью употребления отрицательного наречия never 'никогда' (англ. never cook 'никогда не готовят', never clean 'никогда не убирают'). Отрицательная ироническая оценка прослеживается и в словосочетании fathers with no responsibility for children 'отцы, не несущие ответственности за детей', в импликакативном значении выражений visit strip clubs 'посещают стриптиз-клубы', talk about cars 'разговаривают о машинах'. Гипотетическое звучание выражения men are expected to take care of themselves 'предполагается, что мужчины заботятся о себе сами' подразумевает, что в реальности мужчины этого не делают. Очевидно, что такие социальные роли мужчин не вызывают одобрения женщин.

В оценке социальных ролей представителей своего пола мужчины четко выделяют три сферы своей деятельности: обеспечение семьи (англ. breadwinner 'добытчик', head of household 'глава семьи'), карьера и общественная деятельность (англ. work, career 'работа, карьера', authority figures 'представители власти'), увлечения (going in for sports 'занятия спортом', fishing 'рыбалка'). Некоторым образом самокритично в устах мужчин звучит drinking 'употребление алкоголя', которое, таким образом, занимает достаточно значительное место в жизни мужчин, поскольку упоминается практически каждым информантом и мужского, и женского пола. По мнению мужчин, в жизни женщин просматривается достаточно разно- 
плановая деятельность в семье (англ. carer of the family 'человек, заботящийся о семье', home-maker 'хозяйка дома, мать семейства, жена, создающая уют', domestic affairs 'домашние дела', mother 'мать'). Мужчины считают, что женщины также активно занимаются благотворительной деятельностью (англ. charity work (fund raising, care in the community (young and elderly) 'благотворительная деятельность (сбор денег, благотворительная деятельность, забота и помощь молодым и пожилым людям)'), посвящают свое время увлечениям (англ. amateur activities (choirs, dramatics) 'любительская деятельность (хоровое пение, театр)'). По мнению мужчин-носителей английского языка, карьера и профессиональная деятельностью не входит в состав основных социальных ролей женщин.

В связи с этим представляется интересной точка зрения Леви-Стросс, который считает, что половое разделение труда не является специализацией по биологическому признаку и должно иметь другую цель [19]. Этой целью является, по его утверждению, обеспечение союза женщин и мужчин через создание наименьшей трудоспособной экономической единицы, насчитывающей, по крайней мере, одного мужчину и одну женщину. Таким образом, разделение социальных ролей можно рассматривать как “запрет" на “одинаковость" мужчин и женщин, запрет, разделяющий представителей полов на две взаимоисключающие категории, запрет, который усугубляет различия между полами и тем самым создает гендер [19]. Безусловно мужчины и женщины различны, но они не являются взаимоисключающими категориями, поскольку различия между мужчинами и женщинами проходит по ряду черт, а диапазон их варьирования часто перекрывается. Взгляды и подходы К. Леви-Строса разделяет А. Льюис, работы которого свидетельствуют об актуальности социальной антропологии и ее междисциплинарном характере (см., например, [20]).

\section{2. Социальные роли мужчин и женщин в украинском языке}

Анализ ответов респондентов на вопрос о социальных ролях мужчин и женщин показывает, что мнение участников эксперимента обоего пола относительно социальных ролей друг друга в целом совпадает. Однако, как и англоязычные информантки, носительницы украинского языка предлагают более разнообразный набор социальных ролей. В отличие от ответов на данный вопрос информантов-англичан у украинских информантов не зафиксирована отрицательная оценка отмеченных социальных ролей, то есть восприятие своего и противоположного пола и мужчинами и женщинами является позитивным. Анализ материала эксперимента также показывает, что участники эксперимента обоего пола в целом разграничивают две сферы своей деятельности: семейную и общественную. Мужчина воспринимается как здобувач грошей, голова сім'ї, господар, женщина - как мати, продовжувачка роду, вихователь дітей. Эти роли являются ключевыми и включены в набор всеми информантами. В отличие от материнства отцовство не отмечено как приоритетная социальная роль ни самими мужчинами, ни женщинами. Следует отметить, что на ранних этапах эволюции человека материнство являлось единственной установленной формой семейных связей. В отличие от отцовства материнство представляло собой непреложный биологический факт и служило основой для социальных организаций сообщества. Восприятие роли сообщества в разных социокультурных общностях исследовались разными специалистами [6; 11; 14; 22]. Например, М. Мид показала различия в отношении к сущности и значению материнства в контексте той или иной культуры, их зависимости от социальных установок. Как свидетельствует эксперимент, в 
украинском обществе отмечается высокая степень ориентации женщин на материнство, на выполнение ими социальной роли продовжувачки роду, вихователя dimeй. Представители обоего пола - носители украинского языка отмечают абсолютный приоритет этой социальной роли.

Как показывает анализ материала, общественная сфера ассоциируется в большей степени с профессиональной деятельностью мужчин и женщин. В этом заключается основное отличие представлений о социальных ролях представителей разных культурных социумов. Спектр профессиональных ролей мужчин и женщин разнообразен. По мнению респондентов-мужчин, для представителей сильного пола найхарактерніше заняття політикою, різними видами бізнесу, они являются лідерами, керівниками, займають вищі посади и в целом займаються своєю кар'єрою для створення матеріальної бази своєї сім'ї, а также для того, чтобы займати значне місце у суспільстві. Мужчины считают, что в отличие от женщин они способны заниматься аналитической деятельностью (cтратег, психолог), а также тяжелым физическим трудом (виконувати важку працю). Респондентки полагают, что, с одной стороны, чоловікам властиві тіж самі ролі, що і жінкам, а, с другой стороны, чоловіки грають найголовнішу роль у всьому, їх ролі більш відповідальні, ніж у жінок.

В отличие от мужчин-носителей английского языка украинские мужчины полагают, что такие основные роли женщин, как мати, домогосподарка могут сочетаться с профессиональной деятельностью женщин (жінки приймають участь у всіх сферах соціальної діяльності і встигають підтримувати нормальне сімейне життя), хотя женщинам гораздо труднее добиться успеха в карьере (жінки усе більше інтегруються у ділову сферу, але не так, як чоловіки, становятся бізнеследі). Сами респондентки придерживаются мнения, что женщинам по силам заниматься любыми видами деятельности (не тільки суто «жіночими», але й «чоловічими»; місце жінки не лише дома за кастрюлями; вони можуть не гірше за чоловіків займати якісь посади ), в частности, женщины не хуже мужчин способны быть руководителями (жінкам треба працювати у сферах, де потрібний розум, розсудливість, розумне керування). Вместе с тем некоторые респондентки считают, что женщины должны работать в так называемых “женских" сферах (але якщо це не призводить до втрати жіночості). Незначительное количество респонденток признает, что у всіх сферах, крім господарства, жінки лише наздоганяють чоловіків. Отдельные респонденты считают, что благодійна діяльність может быть чисто женской сферой. Периферийное положение этого вида социальной деятельности в наборе социальных ролей, предложенных носителями украинского языка, объясняется недостаточной распространенностью благотворительности в нашем обществе. Следует отметить, что проблема досуга также является периферийной в спектре социальных ролей, выделенных респондентами. Это объясняется тем, что свободное время и женщин, и мужчин сведено до минимума. Целесообразно процитировать Майкла Киммеля: «Гендер не просто система классификации, которая сортирует, разделяет и социализирует биологических особей мужского и женского пола по их социальным ролям. Гендер еще выражает универсальное неравенство между мужчинами и женщинами. Когда мы говорим о гендере, - мы говорим также об иерархии, власти и неравенстве, а не только о простом различии» $[17$, c. 1$]$.

Представляется, что в определении социальных ролей в украинском обществе доминирует фактор “биологической” аргументации, который имеет “мужскую” интерпретацию. Это относится к точке зрения на семью и распределение ролей в ней, на проблемы ответственности за детей, на выбор профессии и карье- 
ру. Распространение установок на традиционную патриархальную семью с ответственностью матери за детей, зачастую отсутствие у женщин возможностей сделать карьеру и обеспечить свой профессиональный рост, комплекс женской жертвенности приводит к обострению межличностых отношений в обществе. Так воспроизводится гетеросексуальная патриархальная идеология противопоставления биологических полов. Анализ социальных ролей показывает, что женщина - это хранительница очага, организатор мужского потребления, а мужчина - хозяин, творец, существо высшего порядка.

\section{Выводы}

Результаты эксперимента свидетельствуют об отличиях в представлениях носителей английского и украинского языков о социальных ролях. Как показывает анализ материала, в украинском социуме начала XXI ст. общественная сфера ассоциируется в большей степени с профессиональной деятельностью мужчин и женщин, причем отмечается высокая степень ориентации женщин на материнство. В английском языке за пределами семьи определяются в основном мужские роли, а роли женщин являются в основном семейными и находятся в сфере личных, эмоциональных связей. В отличие от носителей английского языка украинские мужчины полагают, что такие основные роли женщин, как мати, господарка могут сочетаться с профессиональной деятельностью женщин, хотя женщинам гораздо труднее добиться успеха в карьере. Англоязычный материал подтверждает, что мужчины четко выделяют три сферы своей деятельности: обеспечение семьи, карьера и общественная деятельность, увлечения. Женщинам присуще занятие благотворительностью, они также уделяют время своим увлечениям. Эти виды социальной деятельности занимают периферийное положение в наборе “женских" ролей в украинском обществе, что объясняется недостаточной распространенностью благотворительности в украинском обществе, а также тем, что свободное время, необходимое для занятий увлечениями сведено до минимума. В целом представления и мужчин, и женщин относительно социальных ролей своего и противоположного пола совпадают. Разноплановость, а также наблюдаемое несовпадение и несоответствие социальных ролей мужчин и женщин можно объяснить как следствие отношений, посредством которых вырабатываются и упорядочиваются биологический и социальный пол (гендер). Как показал анализ материала, на женщин накладывается больше, чем на мужчин, ограничений в системе выполняемых социальных ролей. Анализ социальных ролей показывает, что для украинского языкового сообщества в большей степени, чем для англоязычного, характерна установка на традиционную патриархальную семью, в которой женщина является хранительницей очага, организатором мужского потребления, а мужчина - хозяином и главой семьи.

Как показывает изучение литературы по данному вопросу и анализ материала эксперимента, мужчины и женщины в действительности не имеют отделенных одна от другой моделей мира. Женщины, безусловно, имеют свою, отличную от мужчин точку зрения, которая представляет собой попытку локализовать себя в рамках той доминирующей культурной модели мира, которая является “мужским" вариантом модели описания мира, выработанным доминирующей социальной группой. Для преодоления андроцентризма и сексизма необходимы изменения в тех культурных оценках, которые отдают приоритет маскулинности и отказывают женщинам в равном уважении. Поэтому, одной из задач гендерной лингвистики является предотвращение того, чтобы «посредством языка соци- 
ально дискриминировались и ставились в невыгодное положение люди, приукрашивались факты, скрывались проблемы, фальсифицировалась действительность, укоренялись предрассудки, короче говоря: совершалась несправедливость» [23, с. 182]. Особенно перспективным представляется дальнейшее исследование гендерных особенностей речевого поведения с позиции теории языковой личности, что позволяет охватить все характеристики индивида, участвующего в порождении и восприятии осмысленного текста. В связи с ограниченностью исследований, в которых речевое поведение говорящих рассматривалось бы в социолингвистическом контексте, использование в качестве основы "ролевой теории”, имеющей свой источник в теории социализации личности, также является перспективным в аспекте анализа особенностей мужского и женского восприятия мира и их отражения в концептуальной картине мира особенно в сопоставительном плане. Перспективным представляется также анализ эволюции представлений носителей английского и украинского языков о гендерных социальных ролях.

\section{СПИСОК ИСПОЛЬЗОВАННЫХ ИСТОЧНИКОВ}

1. Бессонова О.Л. Социальные роли в концептуальной и языковой картине мира мужчин и женщин: материал эксперимента // Наука і сучасність: зб. наук. праць Національного педагогічного університету імені М.П. Драгоманова. К.: Логос, 2002. - Т. XXXI. - С. 163-173.

2. Кирилина А.В. (сост.). Гендер как интрига познания: сборник статей. - М.: Рудомино, 2000. - $191 \mathrm{c.}$

3. Кон И.С. Социология личности. - М.: Политиздат, 1967. - 383 с.

4. Крысин Л.П. К социальным различиям в использовании языковых вариантов // Вопросы языкознания. - 1973. - № 3. - С. 37-50.

5. Крысин Л.П. Речевое общение и социальные роли говорящих // Социальнолингвистические исследования. - М.: Наука, 1976. - С. 42-52.

6. Мид М. Культура и мир детства. - М.: Наука, 1998. - 429 с.

7. Петренко А.Д. Социофонетическая вариативность современного немецкого языка в Германии. - Киев: Рідна мова, 1998. - 255 с.

8. Тарасов Е.Ф. Социолингвистика и психолингвистика // Теоретические проблемы социальной лингвистики. - М.: Наука, 1981. - 365 с.

9. Тарасов Е.Ф.К построению теории речевой коммуникации // Основы теории речевой деятельности. - М.: Наука, 1979. - 327 с.

10. Щепанский Я. Элементарные понятия социологии. - М.: Прогресс, 1969. - 240 с.

11. Chodorow N. The Reproduction of Mothering: Psychoanalysis and the Sociology of Gender. - Berkely: University of California Press, 1978. - 269 p.

12. Díaz-Morales J.F. Gender-Based Perspectives About Women's and Men's Health // The Psychology of Gender and Health : Conceptual and Applied Global Concerns. Academic Press, 2017. - P. 55-83. URL: https://doi.org/ 10.1016/B978-0-12-803864-2.00002-X.

13. Fishman J.A. Sociolinguistics: a brief introduction. 4th print. - Rowley: Newbury House, 1975. - $126 \mathrm{p}$.

14. Flax J. Postmodernism and Gender Relations in Feminist Theory // Nicholson L. (ed.). Feminism / Postmodernism. - New York, London: Routledge, 1990. - P. 3962. 
15. Göschel J. Dialektgebrauch und Einstellung zu Sprachvariertäten // W.Viereck, ed. Proceedings of the International Congress of Dialectologists in Bamberg. - Stuttgart: Franz Steiner Verlag, 1995. - 876 S.

16. Jilesen M. Soziologie. Eine Einführung für Erzieherberufe. - H. Stam GmbH, Köln Porz, 1992. - 378 s.

17. Kimmel M.S. The Gendered Society. - N.Y.: Oxford University Press, 2000. - 336 p.

18. Kubczak H. Was ist ein Soziolekt. - Heidelberg: Carl Winter, Universitätsverlag, 1979. - $378 \mathrm{~S}$.

19. Lévi-Strauss Cl. Structural Anthropology. - London: Penguin, 1968.

20. Lewis I. Social and Cultural Anthropology in Perspective: Their Relevance in the Modern World. - New York: Routledge, 2017. - 408 p.

21. McCauley R. The Social Art. Language and its Uses. - New York - Oxford: Oxford University Press. Press, 1994. - 241 p.

22. Mead M. Male and Female: A Study of Sexes in a Changing World. - New York, 1949. - $416 \mathrm{p}$.

23. Mills J. Womanwords. - London: Longman, 1989. - 291 p.

24. Oevermann U. Sprache und soziale Herkunft. - Frankfurt, 1972. - 546 S.

25. Park B., Banchefsky S. Women and men, moms and dads: Leveraging social role change to promote gender equality. Advances in Experimental Social Psychology. 2019. - Vol. 59. - P. 1-52. URL: https://doi.org/10.1016/ bs.aesp.2018.10.001.

26. Parsons T. The Structure and Social Action. - New York, 1937. - 775 p.

27. Rondán-Cataluña F. J., Sanz-Altamira B., Peral-Peral B. Gender roles in social network sites from generation Y. // Journal of Technology Management \& Innovation. - Santiago, 2017. - Vol. 12. - No. 4. URL: http://dx.doi.org/ 10.4067/S0718-27242017000400001.

28. Rucker D.D, Galinsky A.D., Magee J.C. The Agentic-Communal Model of Advantage and Disadvantage: How Inequality Produces Similarities in the Psychology of Power, Social Class, Gender, and Race // Advances in Experimental Social Psychology. 2018. - Vol. 58. - P. 71-125. URL: https://doi.org/10.1016/bs.aesp.2018.04.001.

29. Schaumberg R.L., Flynn F. Self-reliance: a gender perspective on its relationship to communality and leadership evaluations. Academy of Management Journal. 60, 2017. P. 1859-1881. doi: 10.5465/amj.2015.0018.

\section{REFERENCES}

1. Bessonova O.L. Social'nye roli v konceptual'noj i jazykovoj kartine mira muzhchin i zhenshhin: material jeksperimenta [Social roles in men's and women's conceptual and language model: experiment material]. Nauka i suchasnist': zb. nauk. prac' Nacional'nogo pedagogichnogo universitetu imeni M.P. Dragomanova [Science and present day: collection of scientific papers of National pedagogical university named after M.P. Dragomanov]. K.: Logos, 2002. T. XXXI. P. 163-173. (In Russ.).

2. Kirilina A.V. (sost.). Gender kak intriga poznanija: sbornik statej [Gender as intrigue of knowledge]. M.: Rudomino, 2000.191 p. (In Russ.).

3. Kon I.S. Sociologija lichnosti [Sociology of personality]. M.: Politizdat, 1967. 383 p. (In Russ.).

4. Krysin L.P. K social'nym razlichijam $v$ ispol'zovanii jazykovyh variantov [To social differences in usage of language variants]. Voprosy jazykoznanija [Questions of Linguistics]. 1973. № 3. P. 37-50. (In Russ.). 
5. Krysin L.P. Rechevoe obshhenie i social'nye roli govorjashhih [Communicaion and social roles of communicants]. Social'no-lingvisticheskie issledovanija [Sociallinguistic studies]. M.: Nauka, 1976. P. 42-52. (In Russ.).

6. Mead M. Kul'tura i mir detstva [Culture and the world of childhood]. M.: Nauka, 1998. 429 p. (In Russ.).

7. Petrenko A.D. Sociofoneticheskaja variativnost' sovremennogo nemeckogo jazyka $\mathrm{v}$ Germanii [Sociophonetic variation of Modern German in Germany]. Kiev: Ridna mova, 1998. 255 p. (In Russ.).

8. Tarasov E.F. Sociolingvistika i psiholingvistika [Sociolinguistics and psycholinguistics]. Teoreticheskie problemy social'noj lingvistiki [Theoretical problems of sociolinguistics]. M.: Nauka, 1981. 365 p. (In Russ.).

9. Tarasov E.F. K postroeniju teorii rechevoj kommunikacii [To building theory of speech communication]. Osnovy teorii rechevoj dejatel'nosti [Fundamentals of theory of communication]. M.: Nauka, 1979. 327 p. (In Russ.).

10. Shhepanskij Ja. Jelementarnye ponjatija sociologii [Basic notions of sociology]. M.: Progress, 1969. 240 p. (In Russ.).

11. Chodorow N. The Reproduction of Mothering: Psychoanalysis and the Sociology of Gender. Berkely: University of California Press, 1978. 269 p.

12. Díaz-Morales J.F. Gender-Based Perspectives About Women's and Men's Health. The Psychology of Gender and Health: Conceptual and Applied Global Concerns. Academic Press, 2017. P. 55-83. URL: https://doi.org/ 10.1016/B978-0-12-803864-2.00002-X.

13. Fishman J.A. Sociolinguistics: a brief introduction. 4th print. Rowley: Newbury House, $1975.126 \mathrm{p}$.

14. Flax J. Postmodernism and Gender Relations in Feminist Theory. Nicholson L. (ed.). Feminism. Postmodernism. New York, London: Routledge, 1990. P. 39-62.

15. Göschel J. Dialektgebrauch und Einstellung zu Sprachvariertäten. W.Viereck, ed. Proceedings of the International Congress of Dialectologists in Bamberg. Stuttgart: Franz Steiner Verlag, 1995. 876 p.

16. Jilesen M. Soziologie. Eine Einführung für Erzieherberufe. H. Stam GmbH, Köln Porz, $1992.378 \mathrm{p}$.

17. Kimmel M.S. The Gendered Society. N.Y.: Oxford University Press, 2000. - 336 p.

18. Kubczak H. Was ist ein Soziolekt. Heidelberg: Carl Winter, Universitätsverlag, 1979. $378 \mathrm{p}$.

19. Lévi-Strauss Cl. Structural Anthropology. London: Penguin, 1968.

20. Lewis I. Social and Cultural Anthropology in Perspective: Their Relevance in the Modern World. New York: Routledge, 2017. - 408 p.

21. McCauley R. The Social Art. Language and its Uses. New York - Oxford: Oxford University Press, 1994. - $241 \mathrm{p}$.

22. Mead M. Male and Female: A Study of Sexes in a Changing World. New York, 1949. $416 \mathrm{p}$.

23. Mills J. Womanwords. London: Longman, 1989. - 291 p.

24. Oevermann U. Sprache und soziale Herkunft. Frankfurt, 1972. - 546 p.

25. Park B., Banchefsky S. Women and men, moms and dads: Leveraging social role change to promote gender equality. Advances in Experimental Social Psychology. 2019. Vol. 59. P. 1-52. URL: https://doi.org/10.1016/ bs.aesp.2018.10.001.

26. Parsons T. The Structure and Social Action. New York, 1937. 775 p.

27. Rondán-Cataluña F. J., Sanz-Altamira B., Peral-Peral B. Gender roles in social network sites from generation Y. Journal of Technology Management \& Innovation. 
Santiago, 2017. Vol. 12. No. 4. URL: http://dx.doi.org/ 10.4067/S0718-27242017000400001.

28. Rucker D.D, Galinsky A.D., Magee J.C. The Agentic-Communal Model of Advantage and Disadvantage: How Inequality Produces Similarities in the Psychology of Power, Social Class, Gender, and Race. Advances in Experimental Social Psychology. 2018. Vol. 58. P. 71-125. URL: https://doi.org/10.1016/bs.aesp.2018.04.001.

29. Schaumberg R.L., Flynn F. Self-reliance: a gender perspective on its relationship to communality and leadership evaluations. Academy of Management Journal. 60, 2017. P. 1859-1881. doi: 10.5465/amj.2015.0018.

Информация об авторе: Бессонова Ольга Леонидовна - доктор филологических наук, профессор, зав. кафедрой английской филологии, ГОУ ВПО «Донецкий национальный университет», 283001, г. Донецк, ул. Университетская 24. профессор кафедры англистики и американистики Университета Св. Кирилла и Мефодия в Трнаве, 91701, Трнава, пл. Херду 2, Словакия.

ORCID iD: http://orcid.org/0000-0002-5171-9790,

Researcher ID 823077

o.bessonova@donnu.ru

Автор прочитал и одобрил окончательный вариант рукописи

Information about the author: Byessonova Olga Leonidovna, Doctor of Philology, Professor, Head of English Philology Department, Donetsk National University, 283001, Donetsk, Universitetskaya Str., 24. Professor of the British and American Studies Department, University of Ss. Cyril and Methodius in Trnava, 91701, Trnava, Nam. Herdu 2, Slovakia

ORCID iD: http://orcid.org/0000-0002-5171-9790,

Researcher ID 823077

o.bessonova@donnu.ru

The author has read and approved the final manuscript

Статья поступила в редакцию / The article was submitted: 01.08.2020

одобрена после рецензирования и доработки / Approved after reviewing and revision: 16.08 .2020

Принята к публикации / Accepted for publication: 27.08.2020

Автор заявляет об отсутствии конфликта интересов./ The author declares no conflicts of interests 